\title{
PAISAJES DE MONTAÑA: EL FERROCARRIL TRASANDINO Y LA CAPTURA ESTÉTICA DE LA CORDILLERA DE LOS ANDES EN LA POESÍA DE GABRIELA MISTRAL ${ }^{1}$ \\ Mountain Landscapes: The railroad and capture trasandino beauty of The Andes mountains in the poetry of Gabriela Mistral
}

\author{
Pablo Lacoste* \\ María Marcela Aranda** \\ Felipe Cussen***
}

\section{Resumen}

La aparición de un medio de transporte como el Ferrocarril Trasandino influyó en la percepción estética que los transeúntes formaron sobre la geografía local. La montaña surge como un elemento fundamental dentro de la poética de diversos autores, entre ellos la poeta chilena Gabriela Mistral. La cordillera y el acceso a ella, desde el Elqui hasta Los Andes, es un elemento troncal de su poesía, adquiriendo características particulares en cada etapa de su creación poética y visión política, las cuales se analizarán en el presente artículo.

Palabras clave: Gabriela Mistral, Ferrocarril Trasandino, montaña, paisaje, poesía chilena.

Abstract

The arrival of the Transandean Railway influenced the aesthetic perception that passers-by formed of the local geography. The mountain appears as a fundamental element of poetry in various authors, including Chilean poet Gabriela Mistral. The mountains and its access, from the Elqui to the Andes, are a core element of her poetry, acquiring particular characteristics at each stage of her poetic creation and political vision, which will be analyzed in this article.

Key words: Gabriela Mistral, Transandean Railway, Mountain, Landscape, Chilean Poetry.

La metamorfosis del paisaje cordillerano se reflejó no sólo en los cambios materiales - surgimiento de ferrocarriles y hoteles - sino también en el plano espiritual, sobre todo porque se marcó una huella en la captura de la belleza escénica de la montaña. Hasta la llegada del siglo XX, y con él, del servicio ferroviario, las imágenes de la cordillera estuvieron muy condicionadas por el sufrimiento físico de los viajeros a lo largo del camino. El frío excesivo, la fatiga extraordinaria, la sensación de miedo e inseguridad y la abundancia de

\footnotetext{
${ }^{1}$ Este artículo fue elaborado en el marco del Proyecto Bianual 2009-2011 "Corrientes políticas y sociales en América Latina (II)". Directora: Dra. Florencia Ferreira de Cassone. Secretaría de Ciencia, Técnica y Posgrado, UNCuyo. Código 06/F710.
} 
símbolos lúgubres (cruces, cadáveres insepultos, mulas desbarrancadas) actuaban como fuertes disuasivos para que los viajeros no pudieran apreciar favorablemente las bellezas de los ríos, arroyos y montañas nevadas. Son muy escasas las referencias estéticas de los observadores que describieron la cordillera entre los siglos XVI y XIX.

La situación cambió profundamente a partir de la disponibilidad de una infraestructura de transportes que permitió realizar viajes cómodos, rápidos $\mathrm{y}$ seguros. A partir de entonces, la pluma de los escritores comenzó a abandonar las imágenes anteriores, plenas de iconografía fúnebre, para establecer un acercamiento inédito a la valoración estética del paisaje. El F.C.Trasandino generó las condiciones para el desarrollo de una nueva literatura de montaña, en la cual se comenzaron a rescatar los valores estéticos del paisaje.

Los escritores encontraron en el Trasandino un vehículo adecuado para adentrarse en paisajes hasta entonces remotos y, para ellos, inexistentes. A ambos lados de la cordillera, los poetas tomaron el tren, penetraron en las entrañas de la Alta Montaña, y experimentaron el impacto de la belleza escénica. Así lo vivieron autores argentinos y chilenos. Entre aquellos se destacan Alfredo Bufano, Carlos Ponce, Miguel Martos y José Enrique Ramponi. Entre los chilenos, la figura más relevante fue la de Gabriela Mistral, primera iberoamericana en ser galardonada con el Premio Nobel de Literatura (1945).

GABRIELA MisTRAL Y SU LAZO ESPECIAL CON LA MONTAÑA: DEL ELQUI A LOS ANDES

La poeta chilena lideró el proceso de descubrimiento de la belleza de Alta Montaña para luego expresarlo en forma de arte. Sintió la crudeza de la geografía y de la historia chilenas, a las que convirtió en su propia fortaleza, tal como menciona Oyarzún Peña: "como una estatua de piedra alzada en medio del paisaje", de donde es posible extraer "la fuente de agua pura que lo hace fértil" (37). El conjunto de la obra mistraliana reflejaría, después, este lazo especial que construyó con la cordillera de los Andes, desde donde pudo pensar y sentir América de una forma diferente y original.

La aproximación de Lucila Godoy con la montaña fue gradual y se prolongó durante su infancia y juventud. Los primeros años de su vida, transcurridos en el valle del Elqui, le permitieron construir un hábito de cercanía con la cordillera. Bautizada en Vicuña, y criada en Monte Grande, la futura Gabriela Mistral se acostumbró a dialogar con un entorno de montañas, valles y árboles. Durante sus doce primeros años (1889-1901) vivió en ese entorno. Luego se trasladó a La Serena donde se dedicó a estudiar y trabajar. De esa época data su trunca relación amorosa con Romelio Ureta Carvajal, en el pueblo La Cantera en Coquimbo. Promesas incumplidas y el robo de dinero del ferrocarril del que era empleado 
terminaron con el suicidio de él y Gabriela volcó esta experiencia traumática en "Los sonetos de la muerte". Con esta composición ganó los Juegos Florales de Santiago en 1914, concurso organizado por la Sociedad de Artistas y Escritores de Chile, y que le hicieron trascender el estrecho círculo provinciano. En ellos ya se refleja el amor entrañable de Gabriela por la tierra chilena. Así, esta tierra pasa a ser por una parte la tumba de su amado, el receptáculo de su instinto maternal y al mismo tiempo el espacio de la memoria, como un imán que la seguirá atrayendo más allá de sus viajes por el mundo:

Del nicho helado en que los hombres te pusieron, te bajaré a la tierra humilde y soleada.

Que he de dormirme en ella los hombres no supieron, y que hemos de soñar sobre la misma almohada.

Te acostaré en la tierra soleada con una dulcedumbre de madre para el hijo dormido, y la tierra ha de hacerse suavidad de cuna al recibir tu cuerpo de niño dolorido ...

Me alejaré cantando mis venganzas hermosas, ¡porque a ese hondor recóndito la mano de ninguna bajará a disputarme tu puñado de huesos! (Antología Poesía, 67).

Este mismo carácter doble, de vida y muerte, es el que más adelante se observará en el poema "Valle del Elqui", incluido en Poema de Chile:

Tengo de llegar al Valle

que su flor guarda el almendro

y cría los higuerales

que azulan higos extremos,

para ambular a la tarde

con mis vivos y mis muertos (Antología Poesía, 486).

Volvió a vivir en la montaña poco después, para trabajar como profesora de Castellano, Historia y Geografía en el liceo de niñas de la ciudad de Santa Rosa de los Andes (1912-1918). Fue el reencuentro de Lucila con el entorno de montañas. En efecto, el contacto profundo con la cordillera, primero en el valle del Elqui y luego en Los Andes, causaron una profunda impresión en Gabriela Mistral. Este proceso se ha estudiado de forma irregular, pues se ha sobrevalorado la etapa del Elqui, y se ha minimizado el ciclo de Los Andes. Así lo interpreta el historiador local Carlos Tapia Canelo

De la influencia del valle del Elqui en la obra mistraliana sabemos bastante, gracias a las investigaciones que se han hecho de Gabriela Mistral en ese enigmático rincón de nuestro territorio. Pero sus investigadores y biógrafos no han vuelto la mirada, salvo mínima expresión, al valle del Aconcagua y especialmente a Los Andes, 


\section{Pablo Lacoste, María Marcela Aranda, Felipe Cussen}

ciudad en la cual la poeta permaneció el mayor tiempo de su viajada vida adulta. Indudablemente que la hermosa tierra andina, aferrada a la cordillera de los Andes, tocó profundamente la sensibilidad de Gabriela Mistral. La poeta encontró en el entorno andino la tranquilidad adecuada que necesitaba para dar cauce a sus creaciones que dormían en silencio en lo más profundo de su ser (182).

Para fundamentar su posición, el autor cita las palabras de la misma poeta, en oportunidad de una entrevista periodística de 1918:

Hasta tal punto fijé mi corazón en este paisaje hebreo de montañas tajeadas y purpúreas, que quiero llamar a Los Andes mi tierra nativa, la tierra de mis preferencias. La otra, Coquimbo, no me dio jamás la misericordia de esta paz ni fue para mí otra cosa que un sorbo renovado de salmuera y de hiel. Y no es solamente que aquí haya escrito casi todos mis versos; es por sobre todo, que aquí me han dejado ser la maestra que Dios quería de mí (182).

El punto de vista de Tapia Canelo es correcto pero incompleto. En efecto, los seis años que Lucila Godoy vivió en Los Andes incrementaron su conexión con la cordillera, pero siempre desde la periferia. No alcanzó a penetrar en Alta Montaña, porque se movía poco. Usualmente permanecía en el pueblo, dedicada a sus clases, su correspondencia, sus poesías y el mate. Así lo reflejó ella misma en una correspondencia suya dirigida a Eduardo Barrios, en 1916: "Yo, como buena gorda, soy perezosa y fácil de fatigarme y con tal amor de la comodidad que acabo de viajar por tres patios con un brasero para sentarme a escribirle. Este es un invierno horrible" (Antología Cartas, 47).

De todos modos, los años de permanencia en Los Andes terminaron de consolidar la cercanía de la poeta con la cordillera, e inspiraron sus primeros escritos sobre el tema, que aluden permanentemente a "la majestad épica del paisaje". Entre 1930 y 1931, mientras dictaba cursos de literatura española contemporánea y de literatura hispanoamericana en Barnard College y Vassar College, en New York, se publicó un texto suyo —en La Nación de Buenos Aires y en Repertorio Americano de Costa Rica - en el cual Gabriela Mistral rescata la estancia del argentino Domingo F. Sarmiento en Santa Rosa de los Andes, en la primera mitad del siglo XIX, cuando estaba en tránsito obligado hacia tierras chilenas, y ella percibe ese paraje y su principal protagonista, la montaña, entregando descripciones sublimes del entorno:

Pedazo a pedazo, la montaña es sorprendente; pero lo más querido de cuanto ella nos regala son su manera de luz y su manera de aire ... y vine a entender cuando viví sin ellas, que aquella luz no solamente orna un valle, sino que nutre a las criaturas y que aquel aire generoso y seco acicatea al pesado y al vivo lo pone en una vibración prodigiosa (Mistral, Escritos políticos, 206). 
La montaña que circunda el valle del Aconcagua abre sus brazos para que Gabriela se refugie y se sienta hermanada con Sarmiento, pues ambos, en Santa Rosa de los Andes, tuvieron una estadía silenciosa pero intensa, signada por la educación y concretada, en uno, con la creación de una escuelita para niños en Pocuro, y en ella, a través de la docencia en el Liceo de Niñas. Sus palabras encierran una infinita ternura y gritan la inmensidad inabarcable del paisaje imposible. Al mismo tiempo, el paisaje que envuelve a los hombres con sus sombras nuevamente se presta para el carácter funerario que se encontraba en "Los sonetos de la muerte", mientras que sus luces rectas parecieran exponer de manera más radical la pequeñez del hombre frente a la grandiosidad de las montañas

La urna de la atmósfera, en que las cosas parecen guardadas para durar, estando más desnudas que en ninguna parte, aproxima la montaña y hace unos juegos prestidigitadores con la distancia; la maravilla está ahí, a una jornada, y se cree tocarle las grescas del lomo y las quiebras del casco crinado. No hay tal; los costurones, las arruguitas que se miran desde abajo, son unas serranías de recorrer en meses y unos valles mayores que el nuestro. La luz acérrima, que le confiesa todos los accidentes y la recorta con una brutalidad gloriosa, nos permite creer a los del valle, que vivimos entre sus pechos y que vivimos siempre a sus pies, o más debajo de ellos, pues al cabo están bien escondidos al igual que los pies de las vírgenes, cuyo manto arrastra" (Escritos políticos 206-07).

El exilio doloroso y el destierro incierto, también presentes en la vida de Gabriela, le permitieron concluir con esta aseveración contundente: "Esta naturaleza de fuerza en la altura y de regaloneo en el valle, ha debido volver soportable a Sarmiento su doble destierro; el de la Argentina y el de la vida urbana que era su preferencia" (207).

Mistral demuestra la misma añoranza por las montañas que no puede olvidar a pesar de su ausencia. En "Montañas mías", las demarca como las presencias tutelares de su infancia, que no dejan de cuidarla:

En montañas me crié

con tres docenas alzadas.

Parece que nunca, nunca,

aunque me escuche la marcha,

las perdí...

$\mathrm{Y}$ aunque me digan el mote

de ausente y de renegada

me las tuve y me las tengo

todavía, todavía,

y me sigue su mirada (Mistral, Antología Poesía, 481).

La presencia del Trasandino comenzó a sentir sus efectos en ella. Aunque no haya viajado a bordo de este tren, todavía, el movimiento que este generaba, el 


\section{Pablo Lacoste, María Marcela Aranda, Felipe Cussen}

constante trajinar de máquinas y pasajeros, el bullicio de la estación y el agudo silbado de las locomotoras, no pudieron menos que llamar su atención y hacerle sentir que la montaña no era un muro, sino un espacio, un camino y un puente, además de un manantial. Una fuente de muchos elementos valiosos, naturales y culturales, que llegaban desde la montaña para fecundar el valle y la vida de su pueblo. Todavía le faltaba la experiencia máxima de penetrar en la Alta Montaña, pero ya tenía un concepto formado de valoración de este paisaje. Así lo reflejó en un texto en prosa de 1922, que acentúa el simbolismo ambivalente de las montañas:

La primera estación del elogio para la Cordillera, terriblemente dueña de nosotros, verdadera matriz chilena, sobre la cual nos hicimos y que, más voluntariosa que la otra no nos deja caer: vivimos bajo ella sin saberlo, como el crustáceo en su caparazón, y nos morimos dentro de su puro señor. En los valles, ello nos quita cielo; en las abras, ello nos lo devuelve. Cordillera regaladora de aguas donde es preciso, y más de nieves que de aguas; pero, en verdad, hogar puro de fuego en unos volcanes adormecidos, que no dormidos. Cordillera despistadora, con su lomo cierto, y que de pronto se acuerda de su vieja danza de ménade y salta y gira con nosotros a su espalda (Mistral Antología Prosa, 1).

\section{POR FIN EN ALTA MONTAÑA}

Las ideas sobre la montaña iban creciendo, poco a poco, en el alma de Mistral. La estadía en Los Andes fue un periodo decisivo, en el cual se fue sedimentando la cercanía de la poeta con la cordillera, como preparando las condiciones para el paso decisivo. Este ocurrió en la década de 1920, cuando Lucila, transformada en figura nacional e internacional por su talento literario, comenzó a viajar por América y Europa en misiones educativas, culturales y diplomáticas. Así, por ejemplo, sólo entre 1925 y 1926 realizó tres viajes entre Chile y Argentina (Gazarian 37-38). Estos desplazamientos se hicieron, muy probablemente, a bordo del Ferrocarril Trasandino, único medio de transporte terrestre entonces disponible entre ambos países. El impacto de estos viajes fue inmediato: volcó sus impresiones en un texto de 1926, en las que una vez más la cordillera es comparada con el lomo de un animal, como si estuviera a punto de levantarse:

¡Esta es por fin la Argentina! Después del Valle de Uspallata, solemne y fantástico, de montañas aleonadas que me prolongan durante mucho tiempo la visión de Chile, viene la pampa. Para un ser criado entre montañas, con la voz enredada entre montañas, con el ojo acostumbrado a saltar de montaña en montaña, la pampa puede no ser hermosa (Mistral, Antología Prosa, 78).

El contraste entre montaña y pampa, entre Chile y Argentina, entre arrieros y gauchos, fue una de las impresiones que la observadora rescató de uno de esos viajes. En otro momento, tuvo oportunidad de expresar ideas más 


\section{Paisajes de montaña: El Ferrocarril Trasandino y la captura estética}

reposadas, sobre todo al referirse a la experiencia de permanecer en Alta Montaña, particularmente la sensación sedante del aire, la belleza nocturna de estrellas tremolantes y los sonidos del infinito. Estas percepciones se reflejaron en uno de sus más bellos textos en prosa, titulado "Recado sobre la cordillera", composición de cinco páginas enfocada en la nieve, el cielo y la música de la montaña. El siguiente fragmento entrega una idea de su contenido:

Los turistas, en una necedad común, se encierran en el hotel de la Cumbre o en el establecimiento de Río Blanco, a jugar a las cartas y a conversar a lo criollo, largo y tendido, después del día de caminatas en un aire tónico que relaja como el vino viejo... El día ha podido ser bueno, pero la noche estrellada que se pierden es la fascinación cabal... La noche andina no puede ponerse en afiches de turismo, al igual que los ventisqueros y los picachos fotogénicos. Y esa noche es nada menos que el fondo de la copa del andinismo, lo más rico y lo más fuerte entre los logros que persiguen los equipos apasionados de la montaña. Los Andes resultan alucinación continua, alucinación de vista y de oído, para cualquiera que no sea el montañés familiarizado con su magia, casado con ella desde que abrió los ojos. Yo guardo de esas noches cierto delirio de estrellas que no supe contar entonces, que no he sabido decir después y que tampoco acertaré a escribir nunca. Otros vendrán que lo consumarán. Mejor es dejarse el éxtasis pecho adentro, que estropearlo dándole a tercias en un relato manco. Después de varias horas de mirar aquel campo de fuegos trémulos, de recoger el zodíaco cortado de casilla a casilla, al igual de calcomanías, el turista rendido de una jornada demasiado fuerte, entre con cierta extrañeza desde esa anchura desatada al cuarto angosto del hotel, alumbrado por una pobre lámpara plebeya (Antología Prosa, 574-75).

Evidentemente, los viajes en el Trasandino y la experiencia de recorrer y estar en Alta Montaña, terminaron de madurar las ideas de Lucila Godoy en torno al paisaje cordillerano. Logró de esta manera un concepto más acabado de la identidad de la montaña. A lo largo de su producción literaria, esta experiencia se haría sentir una y otra vez. Dicha fascinación fue uno de los pilares de la identidad de su obra poética, en la cual la geografía ocupa un lugar sagrado. La imagen de la piedra penetra el alma de Mistral y allí se acrisola con otros elementos de la existencia, para traducirse en una producción literaria que juega con el diálogo entre la naturaleza y la cultura.

Una de las expresiones más acabadas de la conexión de la poeta con la montaña se encuentra en el himno "Cordillera", incluido en la sección América del libro Tala (1938):

Cordillera de los Andes,

Madre yacente y Madre que anda,

Que de niños nos enloquece

$\mathrm{Y}$ hace morir cuando nos falta; 
Que en los metales y el amianto

Nos aupaste las entrañas (Mistral Antología Poesía, 369).

En este poema, la cordillera es elevada ontológicamente a la altura de divinidad. Es una alabanza, una suerte de oración laica, expresada desde un yo colectivo que procura representar a los pueblos de la tierra. Tal como menciona Bussche en el prólogo a Antología mayor: "Desde el punto de vista del discurso, el lenguaje apostrófico, esto es, el estar dirigido el poema en una ferviente apelación, a un tú sagrado, pone los rasgos distintivos de esta forma lírica. Como muchos poemas de la Mistral, en este, la alabanza de lo sagrado constituye una forma ritual" (XXIV).

Un poema en el que esta tendencia se muestra con mayor radicalidad es "Noche andina". Vale la pena confrontarlo con el fragmento recién leído del "Recado sobre la cordillera", en que la poeta ya avisaba que esta visión nocturna excedía la postal turística y tendía más bien hacia una alucinación visual y sonora cargada de simbolismos. Esas líneas parecieran ser el borrador de este poema, en el que se explicita una concepción religiosa:

La noche de nuestra Patria

de estrellas acribillada,

en cedazo a lo divino

está colando las almas.

Hierve así del esplendor

como una Escritura Santa (Mistral, Antología Poesía, 573).

Las estrellas, entonces, forman una caligrafía sobre la noche y mediante su luminosidad transmiten el mensaje divino. Este mensaje no es diurno (es decir, no se asienta en la razón) sino nocturno, ligado a las sensaciones, los sueños y el inconsciente, y que apela de una manera mucho más potente:

Nos habla el tapiz de fuego

con urgidoras palabras.

Parece como que cantan,

de nuestro amor embriagadas (Antología Poesía, 574).

Los personajes del poema acceden, entonces, a una lengua olvidada pero que sigue llamando. La oscuridad es la que permite que pueda ser leída, y la altura de las montañas, como un altar que tiende hacia el cielo, fomenta este himno:

Las estrellas siguen dando

en densa leche dorada

sus pulsaciones ardientes, su exigencia apasionada.

Juntad las señas dispersas

y que bajen en palabras.

Arded más por ayudarnos.

Ya casi sois llamaradas. 


\section{Paisajes de montaña: El Ferrocarril Trasandino y la captura estética}

Ya parece que cantáis

una estrofa única y alta (Antología Poesía, 574).

Este poema representa un simbolismo más universal, pues nos permite observar la Cordillera de los Andes en relación con otras culturas. Tal como señala Juan Eduardo Cirlot en su Diccionario de símbolos, "el simbolismo más profundo de la montaña es el que le otorga un carácter sagrado, refundiendo la idea de masa, como expresión del ser, y la verticalidad" (315-16). Así es como se presenta en los hindúes, iranios, israelitas, germánicos, etc., y su sentido místico proviene precisamente por ser el punto en el que se reúnen el cielo y la tierra (316).

Resulta atractivo, así, interpretar este poema como un punto cúlmine en la evolución religiosa de Gabriela Mistral. Tal como señala Adriana Valdés, su primera identidad arraigada a los límites del valle del Elqui se va perdiendo en la medida en que su paisaje vital se amplía hacia el resto de América y "la cordillera extendida por todo el continente" (217). De modo paralelo, las enseñanzas del cristianismo se van fundiendo con el interés por la teosofía y el budismo, incorporando una visión a veces cercana a la del panteísmo. A juicio de Lila Zemborain, "[e]l flujo armónico de energía entre el 'yo', el universo y Dios crea la posibilidad ficticia de que el 'yo' pueda comprender y comunicarse con todos los entes de la naturaleza e inclusive con la divinidad" (121). En la medida en que se produce esta comunicación directa, es posible "un modo de relación con Dios que se hallaría liberado de la mediación litúrgica oficial" (Rojo, 218). La naturaleza y el cosmos, entonces, son un espacio de vinculación con la trascendencia, donde el lenguaje divino se expresa sin recovecos ni intermediarios pues circula a través de todos los seres. Y la montaña se convierte en el lugar privilegiado donde ese contacto se torna más visible, más poderoso.

En ese mismo libro se incluyen otros pasajes que reflejan los viajes de la Mistral en el Trasandino. Uno de ellos, titulado "Beber", relata una escena en la zona de Río Blanco, a la cual se llegaba a bordo del tren. Allí estuvo la Mistral y se maravilló al contemplar las nacientes del río Aconcagua, a cuyas aguas atribuye un encanto especial:

En el valle del Río Blanco

En donde nace el Aconcagua

Llegué a beber, salté a beber

En el fuete de una cascada,

Que caía crinada y dura

Y se rompía yerta y blanca.

Pegué mi boca al hervidero

Y me quemaba el agua santa,

Y tres días sangró mi boca

De aquel sorbo del Aconcagua (Antología Poesía, 390). 
La poeta rescató los puntos más representativos del recorrido del Trasandino, a ambos lados de la cordillera. Si en la falda occidental de los Andes puso énfasis en Río Blanco y el río Aconcagua, en la vertiente oriental fijó su atención en el cerro homónimo, al cual dedicó un poema concreto:

Yo he visto, yo he visto
Mi monte Aconcagua.
Me dura para siempre
Su loca llamarada
Y desde que le vimos
La muerte no nos mata.
Manda la noche grande,
Suela las mañanas,
Se esconde en las nubes,
Bórrase, acaba...
Y sigue pastoreando
Detrás de la nubada.
Parado está en su sueño
De su cuerpo y de su alma
Ni sube ni desciende,
De lo absorto no avanza;
Su adoración perenne
No se rinde y relaja
Pero nos pastorea
Con lomos y llamarada (Antología Poesía, 510).

Las imágenes de la montaña funcionaron como un manantial inagotable, capaz de empapar buena parte de la producción literaria de Mistral. En el poema "La Cordillera", la montaña es lejana, pero cerca; no pronuncia palabras, pero logra comunicarse; asusta, pero conecta con el niño interior. En el poema "Montaña" se entrega otro juego de imágenes fuertes de este paisaje:

Apuñada y negra la vemos

Como mujer enfurruñada

Vive sola de todo tiempo

Pero nos ama, la Montaña,

$\mathrm{Y}$ hace señales de subir

Tirando gestos con que llama... (Antología Poesía, 240).

Las imágenes de las montañas y los montes con sus pétreas siluetas y sus entrañas metálicas, concentran una fuerza especial para la poeta. La metáfora de la cordillera como mujer enojada reaparece también en otros versos, en donde un niño asustado intenta acercarse a ella para jugar. En otro momento, la descripción de la cordillera se entremezcla con las emociones de la ausencia de la persona amada y los distintos cerros se presentan en forma sucesiva, como 
vistos desde la cadencia del movimiento propio del viaje en tren. Así se refleja en el poema "Fuga", referido a la madre:

Madre mía en el sueño

Ando por paisajes cardenosos:

Un monte negro que se contornea

Siempre, para alcanzar otro monte;

Y en el que sigue estás tú, vagamente,

Pero siempre hay otro monte redondo

Que circundar, para pagar el paso

Al monto de tu gozo y de mi gozo

$\mathrm{Y}$ hay que enhebrar los cerros repetidos,

Sin decir el secreto doloroso:

Que yo te llevo hurtada a dioses crueles

Y que vamos a un Dios que es de nosotros

Y otras veces ni estás cerro adelante,

$\mathrm{Ni}$ vas conmigo, ni vas en mi soplo:

Te has disuelto con niebla en las montañas

Te has cedido al paisaje cardenoso (Antología Poesía, 303).

La descripción de la cordillera como una sucesión de montes o cerros parece reflejar la sensación que se produce en la visión del observador durante el viaje en tren. Mistral juega con estas imágenes para entregar una representación dinámica de la cordillera, cuyo movimiento se eleva como un diálogo con el recuerdo de su madre. Por su parte, el énfasis del color cambiante de las montañas a distintas horas del día, también inspiró a la autora, tal como refleja el poema "Cima":

La hora de la tarde, la que pone

Su sangre en las montañas.

Alguien en esta hora está sufriendo;

Una pierde, angustiada,

En este atardecer el solo pecho

Contra el cual estrechaba.

Hay algún corazón en donde moja

La tarde aquella cima ensangrentada

El valle ya está en sombra

Y se llena de calma.

Pero mira de lo hondo que se enciende

De rojez la montaña.

Yo me pongo a cantar siempre a esta hora

Mi invariable canción atribulada.

¿Seré yo la que baño

La cumbre de escarlata?

Llevo a mi corazón la mano, y siento

Que mi costado mana (Antología Poesía, 107). 


\section{Pablo Lacoste, María Marcela Aranda, Felipe Cussen}

Las palabras de la Mistral representaban la expresión poética resultante de un largo camino interior, que se había iniciado en la periferia de la cordillera durante la vida de infancia y juventud, entre Monte Grande y Santa Rosa de los Andes, para culminar con la penetración hacia el corazón mismo de la piedra, cuando la poeta logró recorrer la zona de Alta Montaña en los viajes del Trasandino. La tierra y la montaña son, evidentemente, algo más que un accidente geográfico: su profundidad y su altura simbolizan el contacto con la maternidad, la muerte y la memoria, así como con la emoción sublime ante la naturaleza y la comunicación con la trascendencia.

\section{CONCLUSIÓN}

Desde el punto de vista cultural, el F.C.Trasandino y los hoteles abrieron las posibilidades para una renovación estética: a partir de entonces fue posible apreciar las bellezas escénicas de la cordillera, con lo cual apareció un panorama de gran fecundidad para las artes, tal como se reflejaría en la exposición de pinturas cordilleranas de Fidel Roig Matons en el hotel de Puente del Inca y en numerosas obras literarias.

Dentro de Chile, el descubrimiento de la montaña como paisaje marcó los años de formación de la mayor poeta nacional, Gabriela Mistral. Ella tuvo oportunidad de vivir en la ciudad de Santa Rosa de los Andes, justamente en la primera década de funcionamiento del servicio internacional del Trasandino. Poseyó el entorno y los estímulos adecuados para levantar la vista, adentrarse en los misterios de Alta Montaña y fecundar con sus paisajes la materia prima de su creación literaria. En esos años, ella firmó un pacto tácito con la cordillera, convirtiéndola en divinizada inspiradora de su obra: "En su luz hablo como alucinada, alucinada todavía junto a la gran Cordillera, mi Cordillera, la Judith tremenda" (Oyarzún Peña 32).

Evidentemente, la montaña desempeño un papel decisivo en la obra mistraliana. Gabriela se sentía una montañesa, mezcla de india y vasca, "una montañesa de cerros pobres" y por lo tanto, "porfiada y de pocas ideas" (27). La belleza sublime de su paisaje empapa su producción literaria, y contribuye a realzar, en conjunto, su percepción del paisaje de Chile y América. Mistral comenta: "Yo me he dormido de niña en el valle del Elqui oyendo a huasos y a cuyanos trocar sucedidos fabulosos de la cordillera, mientras circulaba el mate terriblemente común, y sus caras se me confunden en el recuerdo" (Escritos políticos, 208).

Montaña y ferrocarril, piedra y metal estarán siempre presentes en el recuerdo de la poeta chilena, más aún al estar fuera de su querida patria. En un discurso pronunciado en 1939 sentenciaba:

El europeo... se acerca a Chile pensando que va a encontrar allá adentro sólo un laberinto infernal de montañas. Si llega por vía trasandina, él recibirá en el paso de Uspallata, de golpe y entera, la épica andina; y 
prolongará su aventura visual y respiratoria hasta la ciudad bien nombrada de Los Andes. Las alturas lo toman y dejan por turnos, le roban el cielo y se lo devuelven, lo ciegan de oscuridades para deslumbrarlo enseguida con el resplandor crudo de la nieve (Mistral, Antología Prosa).

Con respecto a los objetivos del presente trabajo, lo interesante es rescatar el proceso por el cual G. Mistral construyó ese contacto con la cordillera. La crítica literaria ha dedicado considerable tiempo y esfuerzo a examinar la influencia del entorno del Elqui en la etapa infantil de Mistral; por su parte, Carlos Tapia Canelo ha reivindicado también la relevancia de sus seis años de permanencia en Santa Rosa de los Andes, que consolidaron en la poeta la familiaridad con la montaña. Igual que en los años de Monte Grande, Lucila tuvo oportunidad de estar en las periferias de la cordillera. Todo ello se coronó cuando la Mistral pudo, por fin, penetrar en el corazón de los Andes, llegar a la zona de Alta Montaña, donde la vegetación desaparece, las estrellas brillan distinto y se perciben los sonidos del silencio. Este camino mágico hacia las entrañas de la cordillera, la Mistral lo recorrió en los brazos del Ferrocarril Trasandino. También lo recorrió a medida que su escritura y sus reflexiones maduraban la posibilidad de incorporar y comprender la carga espiritual de esos paisajes. La naturaleza no sería ya sólo el decorado de sus experiencias vitales, sino el imán que atraía sus miradas y sentimientos, quizás para ofrecer las respuestas que los hombre no han sido capaces de enunciar. Este viaje, en definitiva, merece ser leído, también, como una aventura metafísica, y de ese modo nos obliga a estudiar desde otra mirada los innumerables trayectos vitales de Gabriela Mistral: no sólo como una errancia, sino también como la búsqueda de un sentido cuyas huellas estaban desperdigadas a lo largo de toda la tierra.

Universidad de Santiago de Chile*

Instituto de Estudios Avanzados

Santiago (Chile)

pablo.lacoste@usach.cl

Universidad Nacional de Cuyo**

Facultad de Filosofía y Letras

Mendoza (Argentina)

marcela.aranda06@gmail.com

Universidad de Santiago de Chile***

Instituto de Estudios Avanzados

Santiago (Chile)

felipecussen@gmail.com 
Pablo Lacoste, María Marcela Aranda, Felipe Cussen

BIBLIOGRAFÍA

Bussche, Gastón von dem. "Prólogo de la antología", en Mistral, Gabriela. Antología Mayor Tomo I. Santiago: Cochrane, 1992.

Cirlot, Juan Eduardo. Diccionario de símbolos. Tercera Edición. Madrid: Ediciones Siruela, 1998.

Gazarian Gautier, Marie-Lise. "Gabriela Mistral, la maestra de Elqui”, en Mistral.

Lacoste, Pablo. "El arriero trasandino y el transporte terrestre en el Cono Sur (Mendoza, 1780-1800)". Revista de Indias 68: 244. Madrid: 2008:35-68.

------ "El Ferrocarril Trasandino y la invención de la montaña como espacio social". Entrepasados 24-25. Buenos Aires: 2004:177-198.

El Ferrocarril Trasandino. Un siglo de transporte y politica entre Argentina $y$ Chile. Colección Sociedad y Cultura. Centro de Investigaciones Diego Barros Arana. Santiago de Chile: 2000. Prólogo de Ian Thomson, pp. 470.

Mistral, Gabriela. Escritos políticos. Selección, prólogo y notas de Jaime Quezada. 2a ed. Santiago de Chile: FCE, 1995:203-210.

------ Antología Mayor Tomo I. Prosa. Santiago: Cochrane, 1992.

------ Antología Mayor Tomo II. Poesía. Santiago: Cochrane, 1992.

------ Antología Mayor Tomo III. Cartas. Santiago: Cochrane, 1992.

------ Antología Mayor Tomo IV. Vida y obra. Santiago: Cochrane, 1992.

Oyarzún Peña, Luis. Taken for a ride. Escritura de paso. Compilación y prólogo Thomas Harris E., Daniela Schütte G. y Pedro Pablo Zegers B. Santiago de Chile: Ril editores, 2005.

Rojo, Grínor. Dirán que está en la gloria... (Mistral). Santiago: Fondo de Cultura Económica, 1997.

Tapia Canelo, Carlos. Los Andes, históricas relaciones. Los Andes: Ediciones Alto Aconcagua, 1989.

Valdés, Adriana. Composición de lugar. Escritos sobre cultura. Santiago: Editorial Universitaria, 1995.

Zemborain, Lila. Gabriela Mistral. Una mujer sin rostro. Rosario: Beatriz Viterbo Editora, 2002. 